\title{
EMERGENT INDIVIDUALS AND THE RESURRECTION
}

\author{
TIMOTHY O'CONNOR \& JONATHAN D. JACOBS
}

\author{
Indiana University St. Louis University
}

\begin{abstract}
We present an original emergent individuals view of human persons, on which persons are substantial biological unities that exemplify metaphysically emergent mental states. We argue that this view allows for a coherent model of identity-preserving resurrection from the dead consistent with orthodox Christian doctrine, one that improves upon alternatives accounts recently proposed by a number of authors. Our model is a variant of the "falling elevator" model advanced by Dean Zimmerman that, unlike Zimmerman's, does not require a closest continuer account of personal identity. We end by raising some remaining theological concerns.
\end{abstract}

According to the Christian doctrine of the resurrection, human persons will exist after death; the very individual Augustine of Hippo, whose bones lie entombed in this earth, is either now enjoying a blessed afterlife or will do so at the time of the general resurrection. This doctrine certainly looks doubtful given the general materialist contention that human persons are (without remainder) biological organisms. At death, the organism deteriorates and is reduced over time (or in some cases rather quickly) to a heap of sub-organic matter. Some of this matter makes its way into the living processes of other organisms, including humans. But even if that were not so, and God were to re-assemble and give life to the decomposed bits that once constituted the living Augustine, it does not seem that Augustine himself would be revived. The requisite causal connection between the pre- and post-mortem states of Augustine is missing.

Peter van Inwagen (1978) has proposed one coherent scenario on which God whisks away Augustine's body just prior to death, healed or simply out of harm's way, as the case may be, to the afterlife. Simultaneously, he replaces it with a perfect simulacrum, a process that would be perfectly undetectable by human beings and so consistent with everything we immediately apprehend in experience. Alas, this scenario 
can easily seem a fantastic deception. While it suffices to show the possibility of the bare idea of bodily survival of death, we should hope for something better.

Dean Zimmerman (1999) has proposed an alternative strategy, "the falling-elevator model," on which Descartes' no-deceiver axiom is preserved. Immediately prior to death, Augustine's body fissions into two bodies, one of which remains as his corpse and the other of which jumps through space and time to the afterlife-just as in cartoon physics a person might survive in a falling elevator by jumping out at the last minute. But, Zimmerman argues, the cost of the falling-elevator model is acceptance of a closest continuer theory of identity. On that view, whether Augustine continues to exist over an interval of time depends on facts extrinsic to him throughout the interval. If there are two or more organisms, each connected in the right sort of causal way with Augustine just prior to his death, Augustine does not persist; if there is exactly one, he does. On Zimmerman's model, Augustine satisfies the closest continuer constraint across the point of his passage from this life. The corpse left behind after the fission is, after all, a mere corpse, so at that point there is but one plausible candidate for being Augustine: the living organism in the afterlife. Given that it satisfies plausible intrinsic conditions on being Augustine, the theory says that it is Augustine.

The problem is that we agree with Zimmerman that any closest continuer account of identity is implausible. Whether I survive shouldn't depend, constitutively, on whether a process wholly outside of me takes place, a process simply involving the persistence of another entity altogether. As John Perry says through a fictional character, death by competition is surely "a strange death if ever there was one" (1978, p. 35).

Now, we happen to be unsympathetic to the materialist thesis that token conscious mental states are identical to complex physical states of organisms, presumably complex states of the nervous system. Conscious mental states, while differing greatly among themselves, seem one and all to be fundamentally different, intrinsically, from any complex pattern of neuron firings, which are themselves hierarchically nested physical structures of enormous complexity. Mental states exhibit relatively basic or unstructured qualitative and intentional features that separate them sharply from anything recognizably material. Nevertheless, we are sympathetic to a second materialist thesis that a human person is a material 
being, a specific kind of biological organism, even if one that exhibits ontologically emergent features unseen in other wholly unconscious material systems. ${ }^{1}$

Finally, we are also committed to the Christian doctrine of the resurrection of the dead. Are we stuck with the unpalatable choice of accepting either van Inwagen's body snatcher proposal or Zimmerman's falling-elevator model and, with it, a closest continuer theory of identity? No-or so we shall argue. First, we present Zimmerman's model, together with his argument that a view of human beings as biological organisms is committed to the closest continuer theory. Second, we present our preferred, emergent individuals view of human persons. Third, we provide an alternative falling-elevator model to Zimmerman's, one that is based on the emergent individuals view of human persons and that is committed to neither the body snatcher proposal nor the closest continuer theory of identity. Fourth, we briefly contrast this model of the resurrection with two alternatives. We end by raising some remaining, theological concerns.

\section{JUMPING ANIMALS AND CLOSEST CONTINUERS}

Consider, first, the persistence of a simple-that is, partless-object. What is it for such an object to persist from moment to moment? Plausibly, while the endurance of a basic individual is not analyzable, it has immanent causal constraints (Zimmerman, 1997a). If $x$ endures from t1 to $\mathrm{t} 2$, the intrinsic state of $\mathrm{x}$ at $\mathrm{t} 1$ must have been among the causal factors giving rise to x's being the way it is at $\mathrm{t} 2$. Otherwise, we would absurdly allow the possibility that its state at time $t 2$ was wholly determined by extrinsic factors over the interval, which is consistent with mere (annihilation together with) duplication. It would be nice to be more precise than the hand-waving "among the causal factors," but we shall not pursue that here. We shall say that when $\mathrm{x}$ and $\mathrm{y}$ meet these causal constraints-whatever precise account of them turns out to be correct- $\mathrm{x}$ is "immanent-causally connected" to $y$.

\footnotetext{
${ }^{1}$ See O'Connor and Jacobs (2003).
} 
Notice, however, that these immanent causal constraints are not the whole story about the persistence of simples. For it seems possible for a simple, $\mathrm{x}$, at t1 to be immanent-causally connected to two simples, $\mathrm{y}$ and $\mathrm{z}$, at a later time, $\mathrm{t} 2$. In addition to the immanent causal connections, there is a further, basic fact of identity. Either y or z (or neither) is identical to $\mathrm{x}$, but this identity does not admit analysis in terms of immanent causal connections. Whether a simple persists or not is a metaphysically bedrock fact. When it comes to simple objects, then, immanent causal connections are necessary but not sufficient for persistence. (The same should be said whether the simple in question is material, an atom, or immaterial, a soul.)

But now consider composite organisms as conceived by van Inwagen. On that view, the lives of organisms are highly organized, self-maintaining events of enormous complexity, involving different swarms of molecules at different times. (We note that van Inwagen (1990, p. 90) states that he is strongly inclined to reject 'holism' regarding living beings, including human beings, and we take his less-than-perspicuous remarks on this matter to commit him to rejecting any kind of emergence in a metaphysical sense. More on the significance of this denial shortly.) The collective persistence of the simple parts of an organism at any time is neither necessary nor sufficient for the persistence of the organism itself at later times. It is not sufficient since the organic unity can be dissolved consistent with the simples persisting outside the life of the organism. Just as clearly, the persistence of any individual particle is not necessary, since organisms can (indeed, must) lose parts. What's more, it looks as though an organism can undergo an entire change-over in parts from one moment to the next and still persist, so long as there are appropriate immanent-causal connections throughout the change. If, as some interpretations of current physics apparently imply, physical simples do not persist for any appreciable length of time, we would not automatically conclude that organisms do not persist. ${ }^{2}$ As a result, the persistence of organisms (at least on this van Inwagen-style view of them) is entirely determined by immanent causal connections.

It is this feature of van Inwagen's account-the necessity and sufficien$c y$ of immanent causal connections for persistence of the organism that

${ }^{2}$ See Zimmerman (1997a) for a brief discussion. 
is the person-that both plausibly leads to the closest continuer theory of identity and allows for the falling elevator model of the resurrection. Suppose that an organism, $\mathrm{x}$, at time $\mathrm{t} 1$ is immanently-causally connected to two bodies, $\mathrm{y}$ at $\mathrm{t} 1+\mathrm{n}$ and $\mathrm{z}$ at $\mathrm{t} 1+\mathrm{m}$, where the first time may be identical to or later than the second time. (When $\mathrm{x}$ is connected to $\mathrm{y}$ and $\mathrm{z}$ in this way, let us say that $x$ has undergone "immanent causal fission.") If both $\mathrm{y}$ and $\mathrm{z}$ are living organisms, then $\mathrm{x}$ is identical to neither. After all, the immanent causal connections between $\mathrm{x}$ and $\mathrm{y}$ are the same as those between $\mathrm{x}$ and $\mathrm{z}$, but $\mathrm{x}$ cannot be identical to both $\mathrm{y}$ and $\mathrm{z}$. If, on the other hand, $\mathrm{y}$ is a living organism and $\mathrm{z}$ is a heap of matter, then $\mathrm{x}$ is identical to $\mathrm{y}$, since they are immanent-causally connected and there is no equallysuited competitor to $y$ for being $x$. Hence, the van Inwagen-style account is plausibly led to affirm the correctness of the closest continuer theory of identity. ${ }^{3}$ Whether $\mathrm{x}$ is identical to $\mathrm{y}$ depends on matters external to $\mathrm{x}$ and $\mathrm{y}$, in particular, on the presence or absence of competitors.

Yet, an attraction of this account is that it allows us to account for the resurrection of the dead. To do so, we need only suppose that, perhaps with the aid of God, Augustine's body undergoes immanent causal fission just before his death, say, at $\mathrm{t}$. The dead matter constituting what some (not van Inwagen) will call his "corpse" at $t 1+\mathrm{m}$ is the way it is because of the way his body is at $t 1$, since it is immanent-causally connected to his body at $\mathrm{t} 1$. But the organism in the afterlife $(\mathrm{t} 1+\mathrm{n})$ is the way it is because of Augustine's body at $\mathrm{t} 1$ as well, since it is also immanent-causally connected to his body at $\mathrm{t} 1$. But the living organism is a better candidate for being identical to his body at $\mathrm{t} 1$ than is a mere corpse. Hence, Augustine exists in the afterlife. He is resurrected in virtue of jumping across space and time.

\section{EMERGENT INDIVIDUALS}

Van Inwagen's account is unacceptable to us because it entails a dubious account of identity over time. It is also unacceptable because of the im-

\footnotetext{
${ }^{3}$ Van Inwagen himself denies this conclusion. Rather than enter into the details of van Inwagen's views concerning organism identity that bear on this matter, we simply refer the reader to Zimmerman (1999, 198-201), who has convincingly shown that van Inwagen must take an implausible stance with respect to certain kinds of possible fission cases.
} 
poverished account of our biological unity, itself flowing from his antiholist commitments. As we see it, fixing the latter defect suffices to fix the former.

To see the way forward, let us think further about the nature and identity of a mereologically simple object, say, Eddie the electron. On our favored ontology, one invoking immanent universals (Armstrong 1997), Eddie has no parts but nevertheless has several features-spin, charge, mass, and so on-as non-mereological constituents. We believe that the arguments to follow in defense of an account of resurrection could be made with equal plausibility, given appropriate adjustments, within an ontology of tropes that dispenses with universals. For expository simplicity, we will not develop the alternative picture. ${ }^{4}$ As universals, these features exist wholly in both Eddie and the other $10^{80}$ or so electrons in our universe. If this much is true, there must be more to Eddie than a mere cluster of universals, since he is a particular thing, and no cluster of universals can yield full determinate particularity, sufficient to distinguish perfect duplicates. Though we cannot argue the matter here, it is plausible that this something extra can only be what we shall call Eddie's particularity (what Armstrong calls Eddie's thin particular): a primitive, non-qualitative, particular component of him that is necessarily unique to him. Eddie, then, is constituted at any time by a cluster of universals plus such a particularity, bound in a sui generis, non-mereological structure. ${ }^{5}$ Crucially, when we consider the identity of Eddie over time, we look to the persistence of his particularity and whichever universals this may entail.

Discussions of the nature of particulars within universals-based ontologies have a long history. ${ }^{6}$ Some authors, especially authors in recent times who hold universals to be transcendent of rather than immanent to objects, appeal to what Robert Adams calls "thisnesses," which he con-

${ }^{4}$ See O'Connor and Jacobs 2003.

${ }^{5}$ Armstrong calls such thin-particular+universals structures 'states of affairs', an event-like category. We do not follow him in this respect. Our difference on this point stems from a difference concerning the nature of persistence over time; Armstrong is a perdurantist, whereas we are three-dimensionalist endurantists.

${ }^{6}$ For more recent discussion, see Black (1954), Adams (1979), O'Leary-Hawthorne (1995), Zimmerman (1997b), Armstrong (1997), and O'Leary-Hawthorne and Cover (1998). 
ceives to be a non-qualitative, nonshareable property of being identical to the individual whose property it is. Therefore, we wish to forestall confusion by emphasizing that particularity, as we conceive it, is in no sense a peculiar sort of property. It is, rather, a peculiar sort of particular: an entity that is incomplete in itself-its 'role' is to particularize a complete object-and that in every case (plausibly) essentially instantiates certain properties and contingently instantiates others. (Granted, such entities can seem mighty peculiar indeed. But every account of objects and their properties has its peculiarities, and we judge this one to be a bit less peculiar, all things considered, than its rivals, and that is all that one can ask of a metaphysical theory.)

Let us now consider the general nature of composite objects. Many ordinary composite objects are such that the following condition holds:

(R) All the object's features are entirely constituted by instantiations of more basic features in and among its parts.

At least, it is commonly thought that this view has been made very plausible by advances in physics and chemistry, though there are dissenting voices. ${ }^{7}$ Suppose this common view is correct. In that case, loose and popular discourse notwithstanding, we should not suppose that such composites have persisting particularities, distinct from the sum of the particularities of each of their parts. We should posit a distinctive particularity only in those composites that exhibit an objective, substantial unity, where this is indicated precisely by the failure of (R).

We here assume that in thinking organisms such as ourselves, ontologically emergent properties do confer on us a substantial unity as thinking biological substances, requiring one to treat human persons as genuine wholes in any adequate characterization of the dynamics of the world. Consider that emergent properties, as primitive features, will make a non-redundant or fundamental difference to the way the world unfolds. A minimally adequate characterization of the world's basic dynamics must refer to all causally-relevant features and their bearers whose causal efficacy is basic - that is, whose efficacy is not in some sense 'inherited' from the features of more fundamental constituting entities.

${ }^{7}$ See, e.g., Laughlin (2005) and Hendry (2006). 
This causal/functional unity does not itself constitute a human person's having a particularity as an enduring thing, but it plausibly implies it. Surely our particularity is primitive, rather than deriving from the primitive particularities of our parts, as our parts are constantly changing. As organized yet constitutionally changing entities exhibiting stably persisting holistic features, we ourselves have distinctive particularities of our own. Even so, as organisms we are mereologically composite systems, wholly composed ultimately by simples. Putting these two facts together, then, we are composite systems that have distinctive particularities and some distinctive features. The emergent things we are are none other than living organisms, even if we have an ontological status not had by composite things, or perhaps even living things, in general. ${ }^{8}$

A delicate question remains: what exactly is the relationship between me, my mereological parts (microphysical simples), and my non-mereological parts (my particularity and my emergent properties)? An antiemergentist account of organisms, such as van Inwagen's, maintains simply that (i) I am necessarily mereologically composed by many simples; (ii) mereological essentialism is false so that no particular simple or set of simples is essential to me; and (iii) composition is restricted so that, to compose me, the simples must be bound up in a life. So long as the very same protracted homeodynamic event that is a particular life persists, I persist. On our emergentist account of composition, by contrast, there is a composite living and thinking object just in case the above mereological conditions of the anti-emergentist holds and the simples are so arranged as to cause and sustain unrealized holistic properties that are bound together with a system-level particularity that does not reduce to the sum of the particularities of the simples. However, it may not suffice to simply affirm the conjunction of these two conditions, one mereological and the other non-mereological. For consider an emergentist version of substance dualism on which I am a mind-body composite that is the mereological sum of a collection of physical simples (none of which I have essentially) and a simple mental substance (which I have essentially) that is non-mereologically composed of a particularity and a collection of mental properties. The view we propose denies that there is any such non-mental substance that is dual to the body. The question

${ }^{8}$ See O'Connor and Jacobs (2003). 
is, why are we entitled to make such a denial, given the existence of an irreducible particularity that instantiates a range of unrealized, personlevel properties?

We see two strategies for clearly distinguishing an emergentist substance dualism from our monistic emergent individuals account. The first is to propose that a person's particularity is non-reductively composed of the particularities of a person's parts. As the parts are everchanging, so would be the composing particularities that constitute the composite's particularity from moment to moment. This proposal has the virtue of making transparent the claim that the emergent individual is indeed a composite: she is mereologically composed of simples, and her particularity is composed of the particularities of her parts. However, we judge the posited non-reductive composition of a particularity to be of doubtful intelligibility. It would stand in relation to its composing particularities in roughly the manner that a functional property is said to stand in relation to its realizing properties on familiar accounts (token identical, but type non-identical). It also seems to share in its problems: one has to squint hard to see two wholly overlapping items at any given time, and one of them (the one posited by philosophical theory) doesn't seem on reflection to do any real explanatory work.

In any case, we prefer a second strategy for preventing a collapse of the emergent individuals account into a form of substance dualism. A person's particularity and emergent properties don't non-mereologically compose a substance distinct from the body because they don't function together as a separate entity, not even as a separate entity that is intimately causally coupled to the body. They have no purely internal dynamics; they don't constitute a nature that is complete, capable of an integrated description independently of the physical-structural states that sustain them. Instead, the structural-physical and emergent mental states of the brain jointly determine subsequent mental as well as relevant physical states of the whole system in a continuous manner. There is but one unity here, not two. We are inclined to suppose that this is somehow reflected in the distinctive nature of a composed person's particularity: unlike the particularity of Eddie the electron, my particularity is precisely something which constitutes me as a particular system, a substantial and composed unity. 


\section{JUMPING EMERGENT INDIVIDUALS}

How might someone who accepts the emergent individual account of human persons think of the resurrection? If one ignored our previous paragraph, one might be tempted to propose a simple solution: while the living Augustine was an emergent, composite substance, his having constituting simples is not essential to him. He has a particularity wholly distinct from those of his simples, and a rich array of emergent features, some of which are no doubt essential to his nature. All that God need do is miraculously preserve his particularity and emergent features, taking over the job of directly sustaining them from the simples whose unified functioning is about to cease. After all, God has been indirectly sustaining the emergent features in virtue of his directly sustaining moment-tomoment the fundamental fabric of the universe, Augustine's constituting simples included.

This simple solution is unsatisfactory. Granted, Augustine's being this individual is a fact distinct from these composing parts' being what they are, as these are parts of Augustine for only a short period of time, while he endures. But if Augustine is nonetheless this system throughout such changes (rather than a distinct substance), his individuality must be somehow intimately bound up with there being some (organized) particles or other which sustain it. Otherwise, the view collapses into substance dualism. It makes no sense to say that this thing is first a composite, then a simple, then again a composite at the resurrection. How could God bring it about that Augustine's emergent state later becomes the state of a new body?

One might suppose, alternatively, that the immanent-causal constraint on identity over time applies only to features at the emergent level. We could then allow that at the moment of Augustine's death, God could generate a particle-for-particle replacement body, and set things up in such a way that this new body's emergent level state is determined in part by the emergent level state of Augustine just before death (and allow that it is not so determined by the intrinsic state of his then-constituting simples, which were on the verge of dissolution, leading to the cessation of their higher level functions).

But such a view posits too weak a connection between Augustine and his underlying matter. It is a kind of substance dualism in all but name, 
as it seems that this system cannot lack all immanent causal links with its constituents. For this reason, Augustine should be thought of as essentially a composite, none of whose composing matter at a given time is essential to him. But further, it is not enough that there be at every instant an emergent, Augustine-like state associated with an underlying Augustine-like body. For God could annihilate Augustine entirely and simultaneously create an exact duplicate of him in the same location, yet this would not be Augustine himself. There must be immanent causal connections at both the underlying and the emergent levels.

But, now you ask, how can this be? If we agree, contrary to the bodysnatcher scheme, that the dead body in the grave is not just a replica of something that once was a living organism, but is instead the remains of such an organism, then that once-living organism is causally connected to the dead body, and not to any glorified individual far away from terra firma. Here, Zimmerman makes an ingenious suggestion: we need suppose only that just before Augustine's demise, God miraculously confers causal powers on the bodily constituents, such that in addition to being immanent-causally responsible for the dying state of the body remaining on earth, they also bear such a connection to the newly generated one. The earthly body, while constituted by the matter that a moment ago had constituted Augustine, is not Augustine, for it lacks the unityconferring emergent features essential to him. The heavenly body retains those features, and so in virtue of its intrinsic state's having the requisite immanent-causal connections to Augustine's earlier state, it is Augustine himself.

We're not so sanguine about the miraculous-addition-of-causal-powers bit, suspecting that it can be bought only by one soft on causation. But no mind: we need only suppose that the features of the constituents of Augustine's body-and as these are no different in kind from the constituents of any material thing, of all material things - and the emergentlevel aspects of Augustine jointly have a hitherto entirely latent tendency to jointly cause the composing simples to fission in the requisite context, which is providentially connected solely to situations of imminent demise. (Perhaps God miraculously brings to bear some requisite additional force-like factor that acts as a co-cause with the relevant disposition.) If you find this wildly implausible, even given theism, you ought to carefully examine the source of your incredulity. Which emergent features, 
if any, are latent in the fundamental constituents of our universe cannot reasonably be assigned any particular a priori probability. They are discovered empirically, having to be accepted, in the phrase of the early $20^{\text {th }}$ century emergentist, Samuel Alexander, with "the natural piety of the investigator." Given that the posited consequence is ex hypothesi not observable to us in this life, who can say?

We said that there are immanent causal relations between the particles of Augustine's body pre-mortem and the particles of both the subsequently dead body and the resurrected body. But which of the latter two collections of particles, if either, is identical to the former collection? Within our framework, nothing vital hangs on this question. Identity of particles is not necessary, at any rate, for the persistence of Augustine, the emergent individual. And there is reason to want to preserve the identity of particles in the case of the dead body: if moment to moment, the identity of most of the particles of the pre-mortem Augustine is preserved, it is uncomfortably close to the body-snatcher scenario to suppose that things are radically otherwise at the moment of death. Furthermore, one might doubt that it could go the other way (particle-identity, for the most part, in the resurrection body). While we have allowed that particles might have an additional propensity, in special circumstances, to effectively spawn duplicates of themselves in a disconnected space, it is harder to concede that the tendency might be inter alia to negate their normal tendency to persist in spatiotemporally continuous circumstances and to produce mere duplicates there instead. One wants to think of emergent propensities as only adding to the non-emergent propensities that are at work in the sub-emergent individuals.

Does the resulting view of the resurrection carry with it a commitment to the closest continuer theory? After all, if it is possible for our constituting matter to fission under circumstances propitious for bodily resurrection, it should likewise be possible under different circumstances, including one in which both products of the fission are living human beings. Or, for that matter, three-way fissioning should be possible, and worse monstrosities still.

We grant the premise, but deny that it forces one to adopt the closest continuer theory. For on our view, immanent causal connections, while necessary, are not sufficient for the persistence of the emergent individual. In this regard, the persistence of emergent individuals is rather like 
the persistence of a simple object. Persistence is a further, basic fact. If there were a fissioning of my body into two duplicates, then one of the resulting emergent individuals may well be me: it will depend on where the distinctive particularity is preserved, if it is preserved at all. It may be impossible to establish empirically the identity, but that is a far cry from saying there is no fact of the matter. The situation parallels precisely the analogue of person-level fission on the substance dualist account that Zimmerman himself favors. Zimmerman has us imagine that our brains' hemispheres were a bit more symmetric, so that they were perfect mirrors of each other. (Our actual brains are not like this, but they do include a lot of functional overlap. Just suppose they differed so as to allow perfect functional overlap.) Of course, I could survive the destruction of one of my actual hemispheres, so surely I could survive the destruction of one of these more symmetrical hemispheres. Further imagine a possible future scenario in which brain transplants are possible, so that you could take one of these hemispheres and put it into someone else's head. Now, Zimmerman's scenario: Take both of my hemispheres out of my body and put each into a separate body. Which one continues my life? Empirically, they are equally well-suited candidates. But on the soul view, Zimmerman claims, “. . . I went wherever my soul went-either with the one half-brain or the other or neither, as the case may be" (1999, p. 198). In other words, one hemisphere, at least, will generate a distinct mental substance, while another may continue to sub-serve the previously existing soul, or perhaps also give rise to a new one. These possibilities will be empirically indistinguishable, while being plainly distinct metaphysically. Just so, we say, on our emergentist account: where the entire organism that I am fissions into two living organisms, I may be the one on the left, the one on the right, or neither. There is a fact of the matter, even if it seems hard to say what determines which fact it is. We agree that the suggestion that there is no factor that determines which way one's particularity goes induces intellectual vertigo, but this is not what we are suggesting. We are denying only that there must be some independently identifiable factor that does the determining. Given a situation of perfect symmetry from an empirical/observable point of view, the determining factor could only be a built-in 'bias' (left, right, or neither) to the latent disposition towards fissioning. Unlike God, we learn of the nature of fundamental dispositions through their effects, and since the 
effects would be indiscernible to us, we could not distinguish the cases absent divine revelation. But to think that this epistemic indiscernibility constitutes a challenge to the intelligibility of what is proposed owes either to a residual trace of positivist anti-metaphysics or, more likely, to one's not having taken fully seriously the suggestion that my particularity is metaphysically basic.

We maintain, then, that it is possible to see, in the abstract, schematic manner characteristic of metaphysical theories, how it could be that God 'preserves us body and soul' through death without resorting to deception. It is no deception that things occur elsewhere and elsewhen as a result of things occurring right before our eyes, provided that events we do seem to see right before us are as they appear (in a rough and ready manner, befitting the limitations of our sensory organs).

\section{A COMPARISON WITH TWO OTHER ACCOUNTS}

We want to briefly compare our view of human persons and how they might survive death with two other views that are superficially similar to it. Lynne Rudder Baker defends what she calls the "Constitution View" of human persons. On this view, human persons are not identical to their bodies, or to a part of their bodies, or to unions of their bodies with nonphysical souls. Constitution, then, is not identity. Human persons are necessarily embodied, but it is not necessary that they have the body they in fact have. They are a partly psychological kind. To be human is to be constituted by a human body. To be a person is to have a 'first-person perspective': "One can think about oneself as oneself and think about one's thoughts as one's own." For this to be the case, it is not enough for one to be conscious. Nonhuman primates are conscious and have points of view, but, she maintains, "they cannot conceive of themselves as the subjects of such thoughts. They cannot conceive of themselves from the first person" (2007, p. 334).

Here's how we are to think of constitution, on Baker's view:

[T] he general idea of constitution is this: when various things are in various circumstances, new things- new kinds of things, with new causal powerscome into existence. Every concrete object is of (what I call) a primary kind. 
A thing has its primary-kind property essentially. So, kind membership (or species membership) is not contingent. The relation of constitution unites things of different primary kinds, and hence things with different essential properties. E.g., a human organism is essentially a member of the human species; a person essentially has a first-person perspective. A human person is a person constituted by a human organism. (2007, p. 337)

She goes on to suggest that "constitution is everywhere: Pieces of paper constitute dollar bills; strands of DNA constitute genes; pieces of cloth constitute flags; pieces of bronze constitute statues" (2007, p. 337). These mundane examples rooted in human conventions make clear that Baker is not thinking of the coming to be of new causal powers in our sense. Constitution is not ontological emergence. She does, to be sure, insist that the coming to be of new materially-constituted kinds is a metaphysical fact, but this contention can't be embraced by someone who takes causation to be a real and basic relation. There would be entirely too much overdetermination of effects if every socially-based kind (such as currency or works of art) results in a co-located object with new causal powers - the piece of paper and the dollar bill, the lump of clay and the statue. Furthermore, it's not at all clear what the constitution relation is, according to its proponents. In a single location, we are told, there are two body-shaped objects that wholly overlap, such that many of their fundamental properties are 'shared', so that when they get on the scale together and it registers 160 pounds, that is the weight of each, rather than the weight of them only collectively. We confess to thinking this to be plainly impossible-there is no relation that would underwrite this strange claim.

Well, these are reasons enough for us, incurable neo-Aristotelian metaphysicians that we are, not to like the constitution account. But perhaps you're unconvinced. Would adopting this picture allow for an elegant scenario of resurrection? Given Baker's view, what is needed is for Augustine's particular first-person perspective to survive death. According to her, there is no immanent-causal constraint whatsoever on this being true. (There is such a constraint on the persistence of Augustine's body, but on Baker's view, Augustine is not identical to a body, he is merely constituted by one.) Well, then, in virtue of what will it be the case that Augustine's first-person perspective comes to be realized in a glori- 
fied body? Here's what she says: "All that is needed is God's free decree that brings about one contingent state of affairs rather than another. If God decrees that the person with body 1 have [Augustine's] first-person perspective, then [Augustine] is the person with body 1 .... Hence, there is no threat from the Duplication Problem" (2007, p. 346).

We find this idea that our persistence is determined by a fact (sameness of first-person perspective) whose identity condition is wholly based in divine decree deeply mysterious. Identity is surely not a wholly extrinsic affair. One wonders what would prevent God from decreeing that glorified body B has Augustine's first-person perspective, despite its sharing none of his earthly psychology.

Baker seems driven to this peculiar way of accounting for survival of death by the perceived unpalatability of the alternatives. Of the alternatives that she criticizes, what she calls 'Animalism' seems closest to our own account. Her chief metaphysical objection to animalism is that it cannot allow for gradual replacement of biological with non-organic parts consistent with persistence of the person. However, this is not clearly true of our own account. She is making what we take to be a fairly large assumption here. Experience teaches that the simples that compose us and all other material things have latent dispositions such that, when organically arranged in the right sorts of ways-in the first instance, into cells, then into more complex structures such as functioning nervous systems-they collectively cause and sustain emergent mental phenomena. It may be that those latent dispositions are sufficiently robust that when matter is arranged in functionally equivalent ways from the level of molecular biology on up-with non-organic components that are differently constituted from but functionally equivalent to ordinary cells-we'd get the same emergent phenomena. Maybe. And if so, our view can cheerfully accept it. We do not define human nature such that we necessarily are organically composed, even if we necessarily start that way. However, we also don't let thought experiments replace actual experiments when it comes to discerning the causal powers of physical things. My arm is not implicated in sustaining my consciousness, and so is not vital to my persistence as a system whose unifying features are broadly psychological. I do not need to worry that replacing it with a bionic equivalent may be an existential threat. When it comes to large-scale replacement of neurons in my cerebral cortex with non-organic counterparts, on the other 
hand - well, let's just say that we wouldn't want to be among the very first people to try that technology, even if they offered it for free!

Finally, we note that Baker's theological argument against Animalism also doesn't carry over to our view. She writes: "In contrast to animalism, the constitution view does not take being a person to be just a contingent and temporary property of beings that are fundamentally nonpersonal (organisms). On animalism, being a person has no ontological significance at all" (2007, pp. 346-7). And she goes on to note in contrast the centrality of personhood to the Christian conception of human beings. However, our emergentist view, unlike the non-emergentist Animalism defended by van Inwagen and others, can equally affirm with Baker that distinctively personal attributes, or at least the potentiality for such, are essential to human beings. Of course, we are not unique among earthly denizens in being organic unities in virtue of a general capacity for conscious experience. But our way of being conscious beings is distinctive, in some respects, within the animal kingdom. And so it seems just as open to us as to a constitution theorist or a mind-body dualist to elaborate an account of the essential properties of human beings adequate to the thesis that we are divine icons, image-bearers, and all that this dramatic declaration in the book of Genesis entails.

Famously, there is another, older view of persons in the general vicinity of our own, also constructed in a way so as to account for the possibility of resurrection: Aquinas's. Just as famously, however, interpreting Aquinas on this topic is a vexed matter. Two key elements of Aquinas's view are clear: (1) the soul is the form of the body, so that the human person during his earthly life consists in a form-matter unity; (2) the soul exists without informing any body from the moment of death until the time of the resurrection, from which point onward the person will exist as a form-matter unity once again. The most vexed issue concerns the identity of the soul in the interim state. Is that disembodied soul identical to the person who died and who will one day be raised again?

Taking inspiration from Aquinas's repeated claim that the soul is not identical to the person, and that, strictly speaking, the departed saints do not pray for us, but their souls do, Christina van Dyke (2007) constructs a Thomistic view of the resurrection similar in certain respects to the one we offer: at death, the person ceases to exist and at the resurrection the 
person exists once again..$^{9}$ Eleonore Stump (2006) claims that this can't be Aquinas's view, as there are theological reasons, some of which we'll briefly mention below, for thinking that the person's existence cannot be gappy. According to Stump, Aquinas thought that while the person is not identical with the soul-and indeed is, before death, constituted by body and soul-the person is nevertheless constituted by the soul alone after death. On either reading of Aquinas, then, the soul has an uninterrupted existence and thereby enables immanent causal connections to hold between the pre-mortem and post-resurrection stages of the person's life without spanning a temporal gap. A fundamental difficulty facing both interpretations is to motivate the claim that it is possible for a mere 'form' of something to persist absent any underlying stuff that it is the form of. This claim seems no less objectionable than would be a claim, rooted in our own account, that my particularity will persist in the absence of any organism that it particularizes. And while Stump's interpretation is textually well-motivated, insofar as Aquinas's claims about the nature and experiences of disembodied souls are scarcely intelligible on the assumption that they are not then souls of the departed (or any other) persons, it has the added burden of the troublesome metaphysics of constitution. What are these persons, now constituted by (but not identical to) souls conjoined to bodies, then constituted by souls alone, and then again by both? Stump suggests that it is no more problematic than an analogous 'animalist' scenario where a person's body is whittled down to her brain, which is kept alive by artificial means. In such a case, she says, the animalist should say that the person is first constituted by her body, then by her brain alone. But there is a better avenue available to the animalist than to indulge in constitutionist double vision. She may instead say that the person once was an intact organism and then became a brain. Saying this will require the animalist to deny that there was, strictly speaking, a brain before the whittling process was completed. ${ }^{10}$ But brains are less integral to the animalist's scheme than souls are to Aquinas's.

For these reasons, we do not see reasons for preferring either Baker's or Aquinas's alternative pictures to the one proposed here.

\footnotetext{
${ }^{9}$ See also Toner (2009).

${ }^{10}$ See Peter van Inwagen (1981).
} 


\section{REMAINING THEOLOGICAL ISSUES}

There are, however, some remaining theological concerns with gappy existence. Here we note just two: First, according to the Doctrine of the Harrowing of Hell, Christ descended into Hades after his death but before his resurrection to free the souls of those who had gone before him. The doctrine seems to imply that there is continued existence after death and before the general resurrection, since the souls of the departed are there to be freed. Second, the practice of petitioning departed saints to pray for us seems to require, if we take it seriously, that the saints exist now and, undoubtedly with the aid of God, hear our prayers and petition God on our behalf.

There are, no doubt, many moves that could be made here, various re-interpretations, deflationary readings or philosophical acrobatics to be performed. But none of those are necessary to undertake here. For note that our account of the resurrection, while explicitly developed in the context of the assumption that our existence is gappy, is nevertheless consistent with the continued, bodily existence of every person after death. ${ }^{11}$ Fairly obviously, it is consistent with immediate resurrection upon death. But it is also consistent with some intermediate, 'incomplete' bodily existence, just sufficient for the persistence of the emergent individual until the time of the resurrection. The assumption of gappy existence can be seen as an attempt to work out how the resurrection of the human person is possible even if some (atypical) form of materialism is true and our existence is gappy. That is a sort of worst-case scenario. It would be significant if it could be shown that the resurrection is possible even in that scenario, and we think it is. ${ }^{12}$

${ }^{11}$ It is also consistent with the claim that God is uniquely involved in the creation of each individual human person.

${ }^{12}$ Special thanks are due to Thomas Sullivan and the department of philosophy of the University of St. Thomas for funding a grant to work on the project. We have presented material from which this article was developed to two audiences: a colloquium at the University of St. Thomas in 2009, and a session of the Society of Christian Philosophers at the Pacific Division meetings of the American Philosophical Association in San Francisco in 2010. We wish to thank both audiences for useful feedback and criticism, especially Rebekah Rice (our commentator in San Francisco), Christina van Dyke, Matthews Grant, Tim Pawl, Michael Rota, Thomas Sullivan, and Dean Zimmerman. 


\section{BIBLIOGRAPHY}

Adams, Robert, "Primitive Thisness and Primitive Identity," Journal of Philosophy 76 (1979), 5-26.

Alexander, Samuel, Space, Time, and Deity Vol.I-II (New York: The Humanities Press, 1920).

Armstrong, David, A World of States of Affairs (Cambridge: Cambridge University Press, 1997).

Baker, Lynne Rudder, Persons and Bodies: A Constitution View (Cambridge: Cambridge University Press, 2000).

Baker, Lynne Rudder, "Persons and the Metaphysics of Resurrection," Religious Studies 43 (2007), 333-348.

Black, Max, "The Identity of Indiscernibles," in his Problems of Analysis (Ithaca: Cornell University Press, 1954).

Hendry, Robin, "Is There Downward Causation in Chemistry?" in Davis Baird, Eric Scerri \& Lee McIntyre, eds., Philosophy of Chemistry: Synthesis of a New Discipline. (Berlin: Springer. 242, 2006), 173-189.

Laughlin, Robert, A Different Universe: Reinventing Physics From the Bottom Down (New York: Basic Books, 2005).

O'Connor, Timothy and Jacobs, Jonathan D., "Emergent Individuals," The Philosophical Quarterly, 53 (2007), 540-555.

O'Leary-Hawthorne, John, "The Bundle Theory of Substance and the Identity of Indiscernibles," Analysis, 55 (1995), 191-6.

O'Leary-Hawthorne, John and Cover, Jan, "A World of Universals," Philosophical Studies 91 (1998), 205-219.

Perry, John, A Dialogue on Personal Identity and Immortality (Indianapolis: Hackett Publishing Co., 1978).

Stump, Eleonore, "Resurrection, Reassembly, and Reconstitution: Aquinas on the Soul," in Bruno Niederberger and Edmund Runggaldier (eds.), Die menschliche Seele: Brauchen wir den Dualismus? (Ontos Verlag, 2006).

Toner, Patrick, "Personhood and Death in St. Thomas Aquinas," History of Philosophy Quarterly 62 (2009).

Van Dyke, Christina, "Human Identity, Immanent Causal Relations, and the Principle of Non-Repeatability: Thomas Aquinas on the Bodily Resurrection," Religious Studies 43(4) (2007), 373-394.

Van Inwagen, Peter, “The Possibility of Resurrection," International Journal of Philosophy of Religion 9 (1978).

Van Inwagen, Peter, “The Doctrine of Arbitrary Undetached Parts," Pacific Philosophical Quarterly 62 (1981).

Van Inwagen, Peter, Material Beings (Ithaca: Cornell University Press, 1990).

Zimmerman, Dean, "Immanent Causation," Philosophical Perspectives, Vol. 11: Mind, Causation, and World, 1997a, 433-71.

Zimmerman, Dean, "Distinct Indiscernibles and the Bundle Theory", Mind, 106 (1997b), 305-309.

Zimmerman, Dean, "The Compatibility of Materialism and Survival: The 'Falling Elevator' Model," Faith and Philosophy 16 (1999), 194-212. 